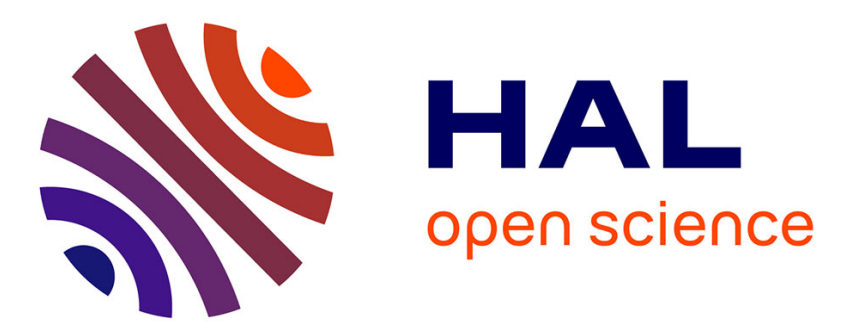

\title{
Driving and damping mechanisms for transverse combustion instabilities in liquid rocket engines
}

\author{
Annafederica Urbano, Laurent Selle
}

\section{To cite this version:}

Annafederica Urbano, Laurent Selle. Driving and damping mechanisms for transverse combustion instabilities in liquid rocket engines. Journal of Fluid Mechanics, 2017, vol. 820, pp. 820 R2/1-820 R2/12. 10.1017/jfm.2017.227 . hal-01548611

\section{HAL Id: hal-01548611 \\ https://hal.science/hal-01548611}

Submitted on 27 Jun 2017

HAL is a multi-disciplinary open access archive for the deposit and dissemination of scientific research documents, whether they are published or not. The documents may come from teaching and research institutions in France or abroad, or from public or private research centers.
L'archive ouverte pluridisciplinaire HAL, est destinée au dépôt et à la diffusion de documents scientifiques de niveau recherche, publiés ou non, émanant des établissements d'enseignement et de recherche français ou étrangers, des laboratoires publics ou privés. 


\section{OATAO \\ Open Archive Toulouse Archive Ouverte}

\section{Open Archive TOULOUSE Archive Ouverte (OATAO)}

OATAO is an open access repository that collects the work of Toulouse researchers and makes it freely available over the web where possible.

This is an author-deposited version published in : http://oatao.univ-toulouse.fr/ Eprints ID : 17945

To link to this article : DOI:10.1017/jfm.2017.227

URL : http://dx.doi.org/10.1017/jfm.2017.227

To cite this version : Urbano, Annafederica and Selle, Laurent Driving and damping mechanisms for transverse combustion instabilities in liquid rocket engines. (2017) Journal of Fluid Mechanics, vol. 820. pp. 820 R2/1-820 R2/12. ISSN 0022-1120

Any correspondence concerning this service should be sent to the repository administrator: staff-oatao@listes-diff.inp-toulouse.fr 


\title{
Driving and damping mechanisms for transverse combustion instabilities in liquid rocket engines
}

\author{
A. Urbano ${ }^{1, \dagger}$ and L. Selle ${ }^{1}$ \\ ${ }^{1}$ Institut de Mécanique des Fluides de Toulouse (IMFT) - Université de Toulouse, \\ CNRS-INPT-UPS, Toulouse, France
}

This work presents the analysis of a transverse combustion instability in a reducedscale rocket engine. The study is conducted on a time-resolved database of three-dimensional fields obtained via large-eddy simulation. The physical mechanisms involved in the response of the coaxial hydrogen/oxygen flames are discussed through the analysis of the Rayleigh term in the disturbance-energy equation. The interaction between acoustics and vorticity, also explicit in the disturbance-energy balance, is shown to be the main damping mechanism for this instability. The relative contributions of Rayleigh and damping terms, depending on the position of the flame with respect to the acoustic field, are discussed. The results give new insight into the phenomenology of transverse combustion instabilities. Finally, the applicability of spectral analysis on the nonlinear Rayleigh and dissipation terms is discussed.

Key words: acoustics, combustion, reacting flows

\section{Introduction}

Combustion instabilities result from the constructive coupling between acoustic waves and combustion. Because unsteady combustion makes noise and acoustic waves modulate flames, when these phenomena occur with specific phase and sufficient gain, they lead to large pressure oscillations. Fluctuations of the order of the mean chamber pressure are not uncommon, which is at best a nuisance but can lead to the destruction of the combustion device. There are many mechanisms through which combustion instabilities can occur. For example, the parametric instability described by Searby \& Rochwerger (1991) results from the wrinkling of a planar flame in a tube, triggered by the unsteady acceleration of the acoustic field. It was also recently demonstrated that even in anechoic environments, flames may respond to self-generated acoustics, resulting in so-called intrinsic thermo-acoustic instabilities (Hoeijmakers et al. 2014;

$\dagger$ Email address for correspondence: aurbano@imft.fr 
Courtine, Selle \& Poinsot 2015). However, as proposed by Rogers \& Marble (1956) and later shown by Poinsot et al. (1987), the vast majority of combustion instabilities stem from the interactions between acoustic eigenmodes of the combustion chamber, coherent vortical structures and flame fronts.

A great deal of progress has been made since the seminal work of Rayleigh (1878), specifically for laminar (Boyer \& Quinard 1990; Schuller, Durox \& Candel 2003; Blumenthal et al. 2013) and swirling turbulent flames (Giauque et al. 2005; Candel et al. 2014). There is, however, to date no comprehensive theory for the prediction and mitigation of combustion instabilities. The lack of fundamental understanding is particularly striking in the field of liquid rocket engines (LREs). Indeed, the high pressure and temperature at which LREs operate hinder the use of modern visualisation techniques and quantitative laser diagnostics. Moreover, most technologies for the injection of propellants use a multitude of coaxial injectors (typically hundreds) arranged in a compact pattern. For these reasons, despite decades of experimental investigation and the growing need for reliable and affordable access to space, combustion instabilities in rocket engines are still not well understood.

With the advent of high-performance computing, large-eddy simulation (LES) has proven to nicely complement experimental data. Single (Selle et al. 2004) and multi-burner (Wolf et al. 2012) configurations have been computed successfully, shedding light on the physical mechanisms involved in combustion instabilities. Over the past ten years, LES has been applied to coaxial diffusion flames at operating conditions relevant for rocket engines (Tucker et al. 2008; Huo \& Yang 2011; Ruiz et al. 2011; Schmitt et al. 2011). More recently, the first LES of a full LRE under unstable operating conditions was performed by Urbano et al. (2016, 2017), giving novel perspectives for the understanding of this type of combustion instability.

The objective of the present study is to take advantage of this unique numerical simulation for a detailed analysis of the driving and damping mechanisms. The configuration and database are first presented in $\S 2$. Then, in $\S 3$, the concept of disturbance energy is presented and applied to the whole combustion chamber. Finally, $\S 4$ focuses on the behaviour of the individual coaxial flames. A methodology that separates the contributions of the two dominant acoustic modes is proposed, shedding light on the coupling mechanisms between acoustics, combustion and hydrodynamics.

\section{Configuration and database}

The configuration is a 42-injector reduced-scale rocket engine that uses cryogenic hydrogen and oxygen as propellants. The oxidiser to fuel ratio is $r=6$ and the mean chamber pressure is $p_{c}=80 \mathrm{bar}$. The operating conditions are transcritical in the sense that the chamber pressure is above the critical pressure of both propellants, and the injection temperature of oxygen is below its critical temperature. This engine was designed and operated at DLR Lampoldshausen, and more details are given by Gröning et al. (2016) and Urbano et al. (2016). Figure 1 presents a longitudinal cut of the temperature field in the combustion chamber and the computational domain, which includes the injection manifolds, the 42 coaxial injectors, the combustion chamber and the outlet nozzle.

For the considered operating conditions, the engine exhibits a strong combustion instability, which is reproduced in the LES, as shown in figure 2 by the temporal evolution of pressure fluctuations, $p^{\prime}$, at a probe in the chamber. The dominant frequency, $f_{1 T}=10700 \mathrm{~Hz}$, corresponds to the first transverse mode (1T) of the 


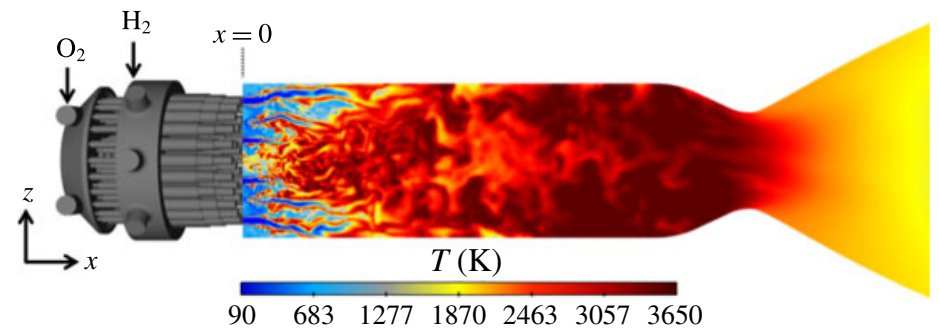

FIGURE 1. Overview of the computational domain and of a longitudinal cut of instantaneous temperature field.
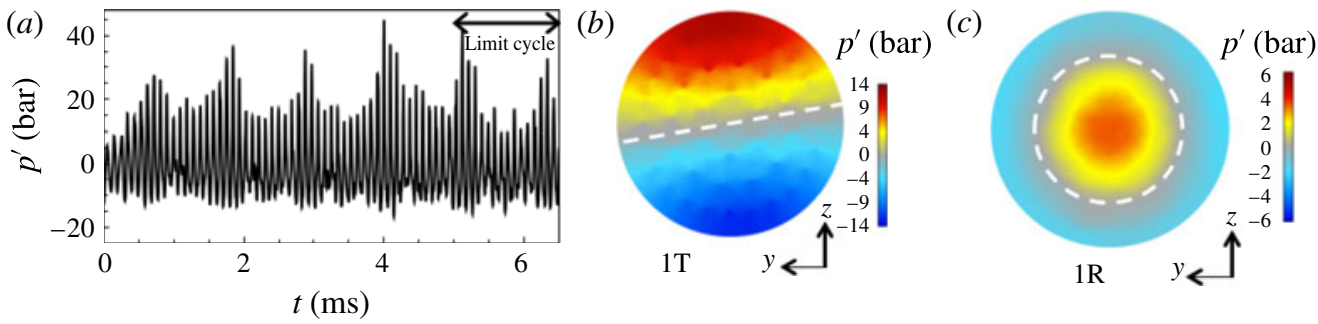

FIgURE 2. (a) Temporal evolution of pressure fluctuations at a probe on the chamber wall. $(b, c)$ Transverse cuts showing the spatial structures of the two dominant pressure modes calculated by Fourier transform. Respective frequencies: $f_{1 T}=10700 \mathrm{~Hz}$ and $f_{1 R}=$ $21400 \mathrm{~Hz}$. The nodal lines are represented by the dashed white lines.

combustion chamber. The LES of Urbano et al. (2016) also demonstrated that the second most energetic peak in the experimental spectra corresponds to the first radial mode (1R) of the chamber at $f_{1 R}=21400 \mathrm{~Hz}$. The spatial structures of these two modes are presented in figure 2, showing the locations of the pressure antinodes and nodal lines. These fields were obtained by performing Fourier transform of $1503 \mathrm{D}$ LES fields, from $t=5 \mathrm{~ms}$ to $t=6.5 \mathrm{~ms}$. The LES was performed with the AVBP solver, and details about the models and numerics can be found in Urbano et al. (2016, 2017).

\section{Balance of disturbance energy}

The present study uses the LES database described in $\S 2$ for the analysis of the disturbance energy, $E_{d}$, which is the extension of the concept of acoustic energy. An exact transport equation for $E_{d}$ was initially derived by Myers (1991) and later extended by Brear et al. (2012). Since we address here a transverse mode, the influence of entropy perturbations is neglected. With the additional assumption of chemical equilibrium, which is consistent with the combustion model, and neglecting viscous terms, the balance equation of Brear et al. (2012) reads

$$
\frac{\partial E_{d}}{\partial t}+F=R+D
$$

The total disturbance energy, $E_{d}$, in the control volume, $V$, and its flux, $F$, through the boundary, $S$, of this volume are written as 


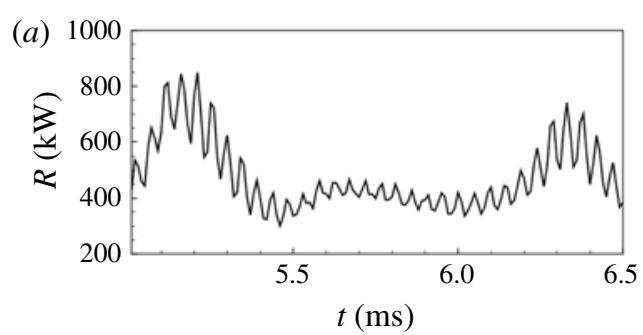

Rayleigh term (equation (3.4))

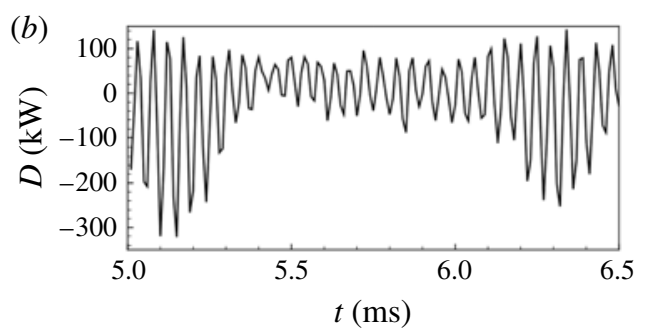

Dissipation term (equation (3.5))

FIgURE 3. Temporal evolution of $R$ and $D$, integrated over the whole combustion chamber.

$$
\begin{gathered}
E_{d}=\int_{V}\left(\rho H^{\prime}-\overline{\boldsymbol{m}} \cdot \boldsymbol{u}^{\prime}-p^{\prime}\right) \mathrm{d} V, \\
F=\oint_{S}\left(\boldsymbol{m}^{\prime} H^{\prime}+\overline{\boldsymbol{m}^{\prime} H^{\prime}}\right) \cdot \boldsymbol{n} \mathrm{d} S,
\end{gathered}
$$

where $\rho$ is the density, $\boldsymbol{u}$ is the velocity, $\boldsymbol{m}(=\rho \boldsymbol{u})$ is the mass flux, $\boldsymbol{\xi}=\boldsymbol{\nabla} \times \boldsymbol{u}$ is the vorticity, $\boldsymbol{\zeta}=\boldsymbol{\xi} \times \boldsymbol{u}, H$ is the total enthalpy and $\boldsymbol{n}$ is the normalised outward normal to $S$. For all variables, the classical Reynolds decomposition is used: $\phi=\bar{\phi}+\phi^{\prime}$. (Reynolds and time averaged variables are equal under the assumption of ergodicity.) On the right-hand side of (3.1), the Rayleigh term, $R$, represents the contribution of combustion, while $D$ accounts for the interaction between acoustics and vortices. They take the forms

$$
\begin{aligned}
& R=\int_{V} \overline{\left(\frac{\alpha}{\rho c_{p}}\right)}\left(p^{\prime} q^{\prime}+\overline{p^{\prime} q^{\prime}}\right) \mathrm{d} V, \\
& D=-\int_{V}\left(\boldsymbol{m}^{\prime} \cdot \boldsymbol{\zeta}^{\prime}+\overline{\boldsymbol{m}^{\prime} \cdot \boldsymbol{\zeta}^{\prime}}\right) \mathrm{d} V,
\end{aligned}
$$

where $\alpha$ is the coefficient of thermal expansion, $c_{p}$ is the constant-pressure specific heat capacity, $p$ is the pressure and $q$ is the heat release rate. It should be noted that the formulation of the Rayleigh term in (3.4) is derived from general thermodynamics and does not assume a specific equation of state. The signs of $R$ and $D$ are not known a priori. As originally stated by Rayleigh (1878), $R>0$ is a necessary condition for a combustion instability to grow. Regarding (3.5), $D>0$ corresponds to coherent flow structures producing disturbance energy, which is the mechanism driving jet and cavity noise. Conversely, $D<0$ indicates a damping of disturbance energy through vorticity.

Using the database described in $\S 2$ and enclosing the whole combustion chamber in the volume $V$, the temporal evolution of $R$ and $D$ is plotted in figure 3. The mean Rayleigh term is positive $(\bar{R}=470 \mathrm{~kW})$, which confirms that the flames are indeed the source of the acoustic activity and the engine is exhibiting a combustion instability. Small fluctuations of $R$ are visible in figure 3(a); their frequency, which is twice that of the $1 \mathrm{~T}$ mode, is discussed in $\S 4.2$. Regarding $D$, displayed in figure $3(b)$, very large fluctuations around zero are observed, indicating that the sign of the transfer of energy between acoustics and vorticity strongly depends on the phase of the eigenmode. At this point, one may speculate that the flow would be perturbed in different ways when the acoustic pressure or acoustic velocity was at its respective peak. This will be 
(a)

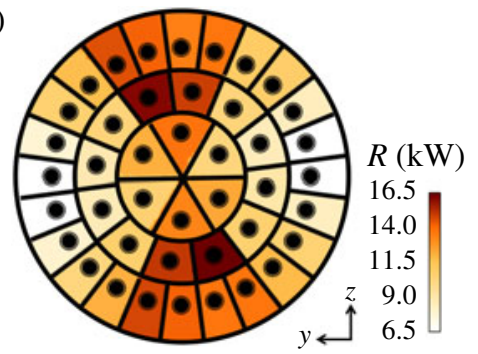

$\bar{R}$ from equation (3.4). (b)

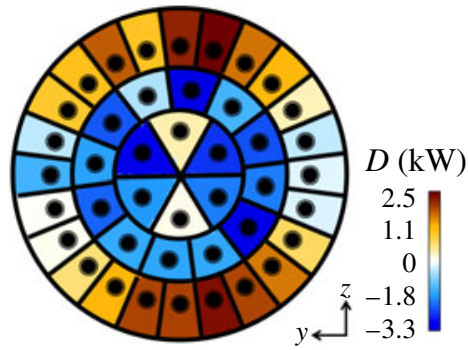

$\bar{D}$ from equation (3.5).

FIGURE 4. Maps of mean Rayleigh and dissipation terms, averaged over volumes isolating individual flames. Time averaged over the limit cycle $(5 \leqslant t \leqslant 6.5 \mathrm{~ms})$.

confirmed in $\S 4$. The mean value of $D$ is negative $(\bar{D}=-14 \mathrm{~kW})$, hence it will be referred to as the dissipation term. The role of $D$ in the dissipation of disturbance energy will be further explained in $\S 4$.

\section{Analysis of individual flames}

The evolution of the source terms in the disturbance-energy balance (3.1), integrated over the whole combustion chamber, only gives a global view of the combustion instability. As expected, it was shown in $\S 3$ that the Rayleigh term, $R$, is driving the instability while the acoustics/vorticity coupling represented by $D$ is globally dissipative. It is now interesting to focus on the spatial distribution of source terms and on the individual response of the flames. For this purpose, the combustion chamber is divided into 42 subvolumes, each enclosing a single flame. Boundaries separating individual flames are located at equal distances from neighbouring injectors. Equations (3.4) and (3.5) are now integrated over these individual volumes to draw maps of the contributions of the flames to the total disturbance energy.

\subsection{Maps of mean contributions}

The distribution of the mean Rayleigh term, $\bar{R}$, for individual flames is shown in figure $4(a)$. Comparing with the spatial structure of the $1 \mathrm{~T}$ mode (figure 2), which is the dominant mode, it appears that the contribution of the flames located at pressure antinodes is greater than that of the flames close to the nodal line. This is consistent with the fact that the Rayleigh term is proportional to the magnitude of the pressure fluctuations. Moreover, $R$ is positive everywhere, meaning that all 42 flames are driving the instability. Regarding the mean acoustics/vorticity interaction term, $\bar{D}$, drawn in figure $4(b)$, one can see that while the outer flames, located at a pressure antinode of the 1T mode, have a positive contribution, the two inner injector rings provide significant dissipation, i.e. $D<0$.

\subsection{Spectral analysis}

The additional information yielded by the spatial distribution of $\bar{R}$ and $\bar{D}$ in figure 4 is now complemented by a spectral analysis. The objective is to isolate the contributions of the two dominant eigenmodes: the 1T and 1R depicted in figure 2. This analysis is conducted here by performing Fourier transforms (FTs) on the time-resolved database 
of 3D LES fields. Similar results (not shown here) have been obtained via the dynamic mode decomposition methodology of Schmid (2010), which may be more efficient for samples with fewer limit-cycle oscillations. Because (3.4) and (3.5) are nonlinear functions of the flow variables, their spectral analysis is not straightforward. It is, however, investigated whether the spectral analysis of $R$ and $D$ could be useful. The present analysis neglects nonlinear interactions between modes, which is a limitation, especially given the large amplitudes encountered in combustion instabilities. The results are therefore not quantitative but still allow qualitative interpretation.

\subsubsection{Contributions of the flames}

The Rayleigh term is analysed first. The pressure and heat release rate spectral decompositions are written as

$$
\left.\begin{array}{l}
p^{\prime}(\boldsymbol{x}, t)=\tilde{p}(\boldsymbol{x}) \cos \left(\omega t-\phi^{p}(\boldsymbol{x})\right) \\
q^{\prime}(\boldsymbol{x}, t)=\tilde{q}(\boldsymbol{x}) \cos \left(\omega t-\phi^{q}(\boldsymbol{x})\right)
\end{array}\right\}
$$

where $\boldsymbol{x}$ is the spatial coordinate, $t$ is the time, $\tilde{p}$ and $\phi^{p}$ (respectively $\tilde{q}$ and $\phi^{q}$ ) are the modulus and phase of the pressure (respectively heat release rate) mode. Combination with (3.4) yields

$$
R=\int_{V}\left[\overline{\left(\frac{\alpha}{\rho C_{p}}\right)} \tilde{p} \tilde{q}\left(\frac{1}{2} \cos \left(2 \omega t-\left(\phi^{p}+\phi^{q}\right)\right)+\cos \left(\phi^{p}-\phi^{q}\right)\right)\right] \mathrm{d} V
$$

The first observation is that for a mode with pulsation $\omega$, the associated Rayleigh contribution oscillates at $2 \omega$. This explains the fluctuations in figure $3(a)$ at twice the frequency of the $1 \mathrm{~T}$ mode. Consequently, in the FT of $R$, the contribution of the 1T mode corresponds to the peak at $2 f_{1 T}$. Its magnitude, denoted $\widetilde{R}$, is obtained from (4.2),

$$
\widetilde{R}=\frac{1}{2} \int_{V} \overline{\left(\frac{\alpha}{\rho C_{p}}\right)} \tilde{p} \tilde{q} \mathrm{~d} V .
$$

On the other hand, taking the average of (4.2) yields

$$
\bar{R}=\int_{V} \overline{\left(\frac{\alpha}{\rho C_{p}}\right)} \tilde{p} \tilde{q} \cos \left(\phi^{p}-\phi^{q}\right) \mathrm{d} V .
$$

Consequently, the mean Rayleigh source term $\bar{R}$ in a given control volume is related to the peak in the FT of $R$ at twice the frequency of the considered mode through

$$
\bar{R}=2 \widetilde{R} \cos \left(\phi^{p}-\phi^{q}\right) .
$$

Equation (4.5) therefore establishes that under the assumption of linear interaction, the FT of $R$ is qualitatively indicative of the contribution of the modes to the disturbanceenergy budget. (Equation (4.5) is strictly valid only when the phase difference $\left(\phi^{p}-\right.$ $\phi^{q}$ ) is constant in $V$.)

The comparison between $\bar{R}$ and the FT of $R$ is presented in figure 5 for the 1T mode. They are qualitatively very similar, despite being quantitatively different. The agreement is favoured by the fact that $R$ is positive everywhere under these conditions. Caution would be needed in the case of sign change, as shown in $\S 4.2 .2$. Figure $5(b)$ confirms that the flames located close to the pressure nodal line have a marginal contribution to the disturbance-energy budget. The flames driving the combustion instability are those located at a pressure antinode. 
(a)

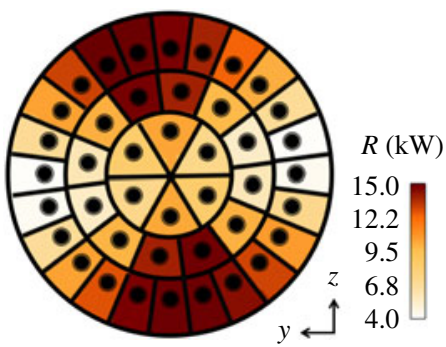

FT of $R(\mathrm{rms})$ at $2 f_{1 T}$. (b)

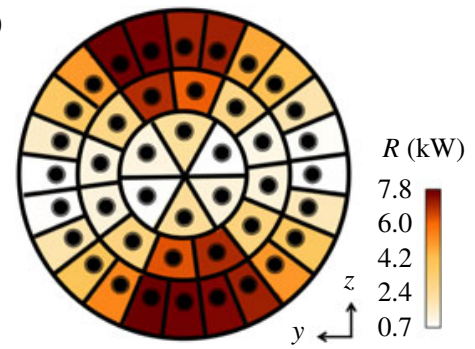

$\bar{R}$ from equation (4.4)

FIGURE 5. Comparison of Rayleigh maps for the 1T mode, obtained using the FT of $R$ and the reconstruction of $\bar{R}$ using the FT of pressure and heat release rate fluctuations.

\subsubsection{Interaction between acoustics and vorticity}

The same methodology is applied to (3.5), which was shown in $\S 3$ to be the main source of dissipation of disturbance energy. Taking advantage of the fact that $\boldsymbol{m} \cdot \zeta=0$, equation (3.5) is recast as (cf. appendix A)

$$
D=\int_{V}\left(\boldsymbol{m}^{\prime} \cdot \bar{\zeta}+\overline{\boldsymbol{m}} \cdot \zeta^{\prime}+2 \bar{\zeta} \cdot \overline{\boldsymbol{m}}\right) \mathrm{d} V .
$$

Using similar notations to those in $\S 4.2 .1$, the spectral decompositions of density, velocity and vorticity fluctuations are

$$
\left.\begin{array}{l}
\rho^{\prime}(\boldsymbol{x}, t)=\tilde{\rho}(\boldsymbol{x}) \cos \left(\omega t-\phi^{\rho}(\boldsymbol{x})\right), \\
u_{i}^{\prime}(\boldsymbol{x}, t)=\tilde{u}_{i}(\boldsymbol{x}) \cos \left(\omega t-\phi_{i}^{u}(\boldsymbol{x})\right), \\
\xi_{i}^{\prime}(\boldsymbol{x}, t)=\tilde{\xi}_{i}(\boldsymbol{x}) \cos \left(\omega t-\phi_{i}^{\xi}(\boldsymbol{x})\right),
\end{array}\right\}
$$

where the subscript $i \in\{1,2,3\}$ indicates the component in the Cartesian frame of reference. Tedious but straightforward algebra shows that (cf. appendix A)

$$
D=\int_{V}\left(D_{1}+D_{2}\right) \mathrm{d} V
$$

where

$$
\begin{aligned}
D_{1}= & \bar{\zeta}_{k}\left[\bar{\rho} \tilde{u}_{k} \cos \left(\omega t-\phi_{k}^{u}\right)+\tilde{\rho} \overline{u_{k}} \cos \left(\omega t-\phi^{\rho}\right)\right] \\
& +\overline{m_{k}}\left[\varepsilon^{i j k} \bar{\xi}_{i} \tilde{u}_{j} \cos \left(\omega t-\phi_{j}^{u}\right)+\varepsilon^{i j k} \tilde{\xi}_{i} \overline{u_{j}} \cos \left(\omega t-\phi_{i}^{\xi}\right)\right]
\end{aligned}
$$

and

$$
\begin{aligned}
D_{2}= & \tilde{\rho} \tilde{u}_{k} \varepsilon^{i j k} \bar{\xi}_{i} \bar{u}_{j}\left[\frac{1}{2} \cos \left(2 \omega t-\left(\phi^{\rho}+\phi_{k}^{u}\right)\right)+\cos \left(\phi^{\rho}-\phi_{k}^{u}\right)\right] \\
& +\overline{\rho u_{k}} \varepsilon^{i j k} \tilde{\xi}_{i} \tilde{u}_{j}\left[\frac{1}{2} \cos \left(2 \omega t-\left(\phi_{i}^{\xi}+\phi_{j}^{u}\right)\right)+\cos \left(\phi_{i}^{\xi}-\phi_{j}^{u}\right)\right] \\
& +\tilde{\rho} \tilde{u}_{k} \varepsilon^{i j k} \tilde{\xi}_{i} \tilde{u}_{j}\left[\frac{1}{4} \cos \left(2 \omega t-\left(\phi^{\rho}+\phi_{k}^{u}\right)\right) \cos \left(\phi_{i}^{\xi}-\phi_{j}^{u}\right)\right. \\
& \left.+\frac{1}{4} \cos \left(2 \omega t-\left(\phi_{i}^{\xi}+\phi_{j}^{u}\right)\right) \cos \left(\phi^{\rho}-\phi_{k}^{u}\right)+\frac{1}{2} \cos \left(\phi^{\rho}-\phi_{k}^{u}\right) \cos \left(\phi_{i}^{\xi}-\phi_{j}^{u}\right)\right] .
\end{aligned}
$$


(a)

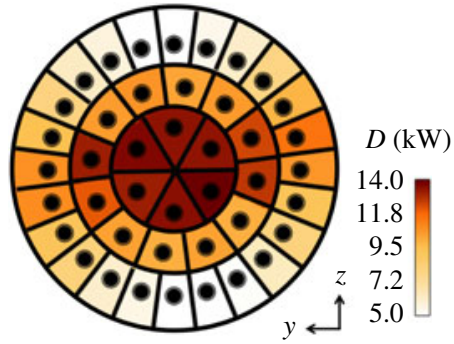

FT of $D(\mathrm{rms})$ at $2 f_{1 T}$. (b)

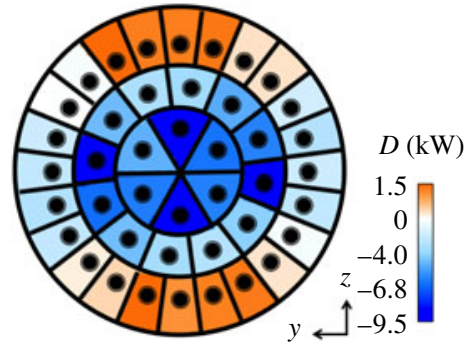

$\bar{D}$ from equation (4.11).

FIgURE 6. Comparison of dissipation maps for the $1 \mathrm{~T}$ mode, obtained using the FT of $D$ and the reconstruction of $\bar{D}$ using the FT of velocity and vorticity fluctuations.

Equations (4.8)-(4.10) indicate that $D$ contains two fluctuating components, one at the frequency of the considered acoustic mode and one at twice this frequency. The corresponding average is

$$
\begin{aligned}
\bar{D}= & \int_{V}\left(\varepsilon^{i j k} \bar{\xi}_{i} \overline{u_{j}} \tilde{\rho} \tilde{u}_{k} \cos \left(\phi^{\rho}-\phi_{k}^{u}\right)+\bar{\rho} u_{k} \varepsilon^{i j k} \tilde{\xi}_{i} \tilde{u}_{j} \cos \left(\phi_{i}^{\xi}-\phi_{j}^{u}\right)\right. \\
& \left.+\frac{1}{2} \varepsilon^{i j k} \tilde{\xi}_{i} \tilde{u}_{j} \tilde{\rho} \tilde{u}_{k} \cos \left(\phi^{\rho}-\phi_{k}^{u}\right) \cos \left(\phi_{i}^{\xi}-\phi_{j}^{u}\right)\right) \mathrm{d} V .
\end{aligned}
$$

Noting that $\overline{D_{1}}=0$, the peak at $\omega$ in the FT of $D$ is not related to the mean dissipation, $\bar{D}$. Unlike the Rayleigh term, the relation between $\bar{D}$ and the second peak in the FT of $D$ is not straightforward because of the many phase differences involved.

The comparison between the FTs of $D$ and $\bar{D}$ is presented in figure 6 for the 1T mode. It appears that because $\bar{D}$ changes sign, the two quantities are qualitatively different. Figure $6(a)$ looks like the absolute value of $\bar{D}$, meaning that the FT of $D$ is not a very useful diagnostic in this case. However, figure $6(b)$ provides a better picture than figure 4(b) regarding the dissipation associated with the dominant acoustic mode. It is clear that the flames located around the nodal line provide massive dissipation. Indeed, flames at a pressure node experience strong transverse acoustic velocity, which is known to induce flapping, jet flattening and flame shortening (Baillot et al. 2009; Hardi et al. 2014; Hakim et al. 2015). These motions take their energy from the acoustic field, explaining the local dissipation.

\subsubsection{Application to the $1 R$ mode}

The same methodology is now applied to the $1 \mathrm{R}$ mode in order to analyse how the flames contribute to $\bar{R}$ and $\bar{D}$ for this mode which has a higher frequency and a different spatial structure (cf. figure 2). The Rayleigh term, displayed in figure $7(a)$, is positive, indicating that the $1 \mathrm{R}$ mode is also unstable. The flames in the inner ring, located at a pressure antinode, provide most of the drive. The outer ring, also at a pressure antinode, has a small contribution, which is speculated to be caused by a phase mismatch between $p^{\prime}$ and $q^{\prime}$. The intermediate ring exhibits a small Rayleigh term, which is consistent with the location of the pressure nodal line. The dissipation map for the $1 \mathrm{R}$ mode plotted in figure $7(b)$ confirms the observation that the flames on the pressure nodal line (i.e. the middle injector ring) provide dissipation. The analysis for the $1 \mathrm{R}$ mode is therefore consistent with that of the $1 \mathrm{~T}$ mode.

It is interesting to discuss the relative importance of the two source terms in the two dominant unstable modes. For the $1 \mathrm{~T}$ mode, the global Rayleigh index is 
(a)

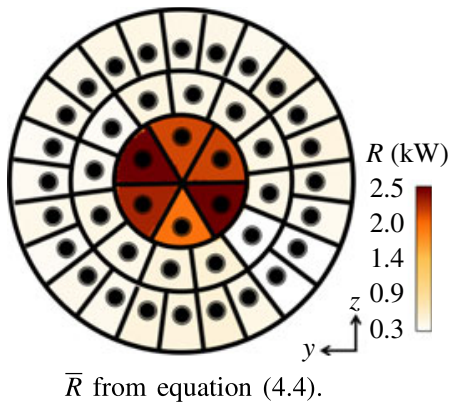

(b)

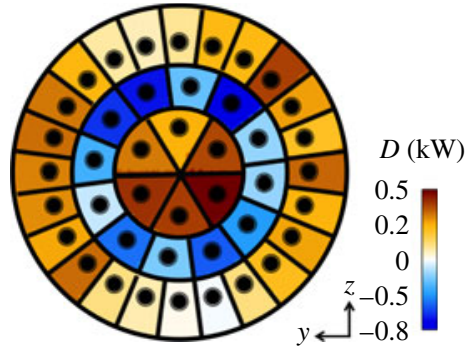

$\bar{D}$ from equation (4.11).

FIGURE 7. Maps of Rayleigh and dissipation terms for the $1 \mathrm{R}$ mode.

$\bar{R}_{1 T}=160 \mathrm{~kW}$ and the dissipation $\bar{D}_{1 T}=-110 \mathrm{~kW}$ (these values are obtained by integrating the maps of figures $5 b$ and $6 b$ ). For the $1 \mathrm{R}$ mode, $\bar{R}_{1 R}=30 \mathrm{~kW}$ and $\bar{D}_{1 R}=1.2 \mathrm{~kW}$. Despite its smaller Rayleigh index, the $1 \mathrm{R}$ mode reaches an amplitude comparable to that of the $1 \mathrm{~T}$ mode because of the large dissipation $\bar{D}_{1 T}$. This illustrates the necessity to understand and quantify dissipation mechanisms, while most studies of combustion instabilities focus solely on the Rayleigh index.

\section{Conclusion}

The analysis of disturbance-energy source terms presented in this work gives novel perspectives on the mechanisms at play during transverse combustion instabilities in an LRE. Using a time-resolved database of 3D fields from an LES, a spectral analysis of the individual flame contributions was presented. The two source terms accounting for the interaction between acoustics and unsteady combustion $(R)$ and acoustics and hydrodynamics $(D)$ were studied. As expected, the well-known Rayleigh index, $R$, drives the instability, with dominant contribution from the flames near a pressure antinode. This indicates that for the determination of the combustion stability, the response of these flames to the bulk pressure fluctuations at the injector outlets seems to be more important than their response to transverse acoustic-velocity fluctuations. A small mean dissipation results from $D$. However, the spectral analysis has shown that flames located at a pressure node provide very large dissipation, affecting the stability of the corresponding eigenmode. The associated mechanism is a transfer of energy from the transverse acoustic-velocity field to the flapping motion of the flame.

\section{Acknowledgements}

This investigation was carried out in the framework of the French-German REST program initiated by Airbus Safran Launchers, CNES, DLR and ONERA. Support provided by Airbus Safran Launchers, the prime contractor of the Ariane 5 and Ariane 6 launchers, is gratefully acknowledged. This work was granted access to the high-performance computing resources of IDRIS under the allocation x20162b7036 made by Grand Equipement National de Calcul Intensif. The research leading to these results has received funding from the European Research Council under the European Union's Seventh Framework Programme (FP/2007-2013)/ERC Grant Agreement ERC-AdG 319067-INTECOCIS. 


\section{Appendix A. Derivation of the dissipation term $(D)$}

Using the definition of the fluctuating quantities, the first term of equation (3.5) is written as

$$
\begin{aligned}
-\boldsymbol{m}^{\prime} \cdot \zeta^{\prime} & =-(\boldsymbol{m}-\overline{\boldsymbol{m}}) \cdot(\zeta-\bar{\zeta}) \\
& =-\boldsymbol{m} \cdot \zeta+\boldsymbol{m} \cdot \bar{\zeta}+\overline{\boldsymbol{m}} \cdot \zeta-\overline{\boldsymbol{m}} \cdot \bar{\zeta}
\end{aligned}
$$

Noting that $\boldsymbol{m} \cdot \boldsymbol{\zeta}=\rho \boldsymbol{u} \cdot \boldsymbol{\xi} \times \boldsymbol{u}=0$, taking the average of (A 1) yields

$$
-\overline{\boldsymbol{m}^{\prime} \cdot \bar{\zeta}^{\prime}}=\overline{\boldsymbol{m}} \cdot \bar{\zeta} .
$$

Using (A 1) and (A 2), equation (4.6) easily follows from (3.5).

The goal is now to write (4.6) in terms of primitive variables - density, velocity and vorticity. For this purpose, the averages and fluctuations of $\boldsymbol{m}$ and $\zeta$ are written as

$$
\begin{gathered}
\overline{\boldsymbol{m}}=\bar{\rho} \overline{\boldsymbol{u}}+\overline{\rho^{\prime} \boldsymbol{u}^{\prime}}, \\
\bar{\zeta}=\overline{\boldsymbol{\xi}} \times \overline{\boldsymbol{u}}+\overline{\boldsymbol{\xi}^{\prime} \times \boldsymbol{u}^{\prime}}, \\
\boldsymbol{m}^{\prime}=\bar{\rho} \bar{u}^{\prime}+\rho^{\prime} \overline{\boldsymbol{u}}+\rho^{\prime} \boldsymbol{u}^{\prime}-\overline{\rho^{\prime} \boldsymbol{u}^{\prime}}, \\
\zeta^{\prime}=\overline{\boldsymbol{\xi}} \times \boldsymbol{u}^{\prime}+\boldsymbol{\xi}^{\prime} \times \overline{\boldsymbol{u}}+\boldsymbol{\xi}^{\prime} \times \boldsymbol{u}^{\prime}-\overline{\xi^{\prime} \times \boldsymbol{u}^{\prime}} .
\end{gathered}
$$

Using (A 3)-(A 6), equation (4.6) is rearranged as (4.8), where $D_{1}$ and $D_{2}$ contain respectively first- and second-order terms in the fluctuating quantities and are given by

$$
\begin{gathered}
D_{1}=\bar{\zeta} \cdot\left(\bar{\rho} \boldsymbol{u}^{\prime}+\rho^{\prime} \overline{\boldsymbol{u}}\right)+\overline{\boldsymbol{m}} \cdot\left(\bar{\xi} \times \boldsymbol{u}^{\prime}+\xi^{\prime} \times \overline{\boldsymbol{u}}\right), \\
D_{2}=\bar{\rho} \overline{\boldsymbol{u}} \cdot\left[\xi^{\prime} \times \boldsymbol{u}^{\prime}+\overline{\boldsymbol{\xi}^{\prime} \times \boldsymbol{u}^{\prime}}\right]+\overline{\boldsymbol{\xi}} \times \overline{\boldsymbol{u}} \cdot\left[\rho^{\prime} \boldsymbol{u}^{\prime}+\overline{\rho^{\prime} \boldsymbol{u}^{\prime}}\right]+\rho^{\prime} \boldsymbol{u}^{\prime} \cdot \overline{\xi^{\prime} \times \boldsymbol{u}^{\prime}}+\overline{\rho^{\prime} \boldsymbol{u}^{\prime}} \cdot \xi^{\prime} \times \boldsymbol{u}^{\prime} .
\end{gathered}
$$

The spectral decompositions of density, velocity and vorticity fluctuations given by (4.7) are used to express the fluctuating quantities in $D_{1}$ and $D_{2}$ and to obtain (4.9) and (4.10). In particular, making use of trigonometric properties, the terms $\rho^{\prime} \boldsymbol{u}^{\prime}, \boldsymbol{\xi}^{\prime} \times \boldsymbol{u}^{\prime}$ and their averages have been replaced by

$$
\begin{gathered}
\xi^{\prime} \times \boldsymbol{u}^{\prime}=\frac{1}{2} \varepsilon^{i j k} \tilde{\xi}_{i} \tilde{u}_{j}\left[\cos \left(2 \omega t-\left(\phi_{i}^{\xi}+\phi_{j}^{u}\right)\right)+\cos \left(\phi_{i}^{\xi}-\phi_{j}^{u}\right)\right], \\
\overline{\boldsymbol{\xi}^{\prime} \times \boldsymbol{u}^{\prime}}=\frac{1}{2} \varepsilon^{i j k} \tilde{\xi}_{i} \tilde{u}_{j} \cos \left(\phi_{i}^{\xi}-\phi_{j}^{u}\right), \\
\rho^{\prime} \boldsymbol{u}^{\prime}=\frac{1}{2} \tilde{\rho} \tilde{u}_{k}\left[\cos \left(2 \omega t-\left(\phi^{\rho}+\phi_{k}^{u}\right)\right)+\cos \left(\phi^{\rho}-\phi_{k}^{u}\right)\right], \\
\overline{\rho^{\prime} \boldsymbol{u}^{\prime}}=\frac{1}{2} \tilde{\rho} \tilde{u_{k}} \cos \left(\phi^{\rho}-\phi_{k}^{u}\right) .
\end{gathered}
$$

Only $D_{2}$ contributes to the time-average dissipation $\bar{D}$ because $D_{1}$, which is first order in the fluctuating quantities, has a zero time-average value. Therefore, taking the average of (A 8) yields

$$
\bar{D}=2 \int_{V}\left[\bar{\rho} \overline{\boldsymbol{u}} \cdot \overline{\boldsymbol{\xi}^{\prime} \times \boldsymbol{u}^{\prime}}+\overline{\rho^{\prime} \boldsymbol{u}^{\prime}} \cdot \overline{\boldsymbol{\xi}} \times \overline{\boldsymbol{u}}+\overline{\rho^{\prime} \boldsymbol{u}^{\prime}} \cdot \overline{\boldsymbol{\xi}^{\prime} \times \boldsymbol{u}^{\prime}}\right] \mathrm{d} V .
$$

Then, making use of (A 10) and (A 12) gives (4.11). 


\section{References}

Baillot, F., Blaisot, J.-B., Boisdron, G. \& Dumouchel, C. 2009 Behaviour of an air-assisted jet submitted to a transverse high-frequency acoustic field. J. Fluid Mech. 640, 305-342.

Blumenthal, R. S., Subramanian, P., Sujith, R. I. \& PolifKe, W. 2013 Novel perspectives on the dynamics of premixed flames. Combust. Flame 160 (7), 1215-1224.

Boyer, L. \& Quinard, J. 1990 On the dynamics of anchored flames. Combust. Flame 82 (1), $51-65$.

Brear, M. J., Nicoud, F., Talei, M., Giauque, A. \& Hawkes, E. R. 2012 Disturbance energy transport and sound production in gaseous combustion. J. Fluid Mech. 707, 53-73.

Candel, S., Durox, D., Schuller, T., Bourgouin, J.-F. \& Moeck, J. P. 2014 Dynamics of swirling flames. Annu. Rev. Fluid Mech. 46, 147-173.

Courtine, E., Selle, L. \& Poinsot, T. 2015 DNS of intrinsic thermoacoustic modes in laminar premixed flames. Combust. Flame 162 (11), 4331-4341.

Giauque, A., Selle, L., Gicquel, L., Poinsot, T., Buechner, H., Kaufmann, P. \& Krebs, W. 2012 System identification of a large-scale swirled partially premixed combustor using LES and measurements. J. Turbul. 6, N21.

Gröning, S., Hardi, J. S., Suslov, D. \& Oschwald, M. 2016 Injector-driven combustion instabilities in a hydrogen/oxygen rocket combustor. J. Propul. Power 32 (3), 560-573.

Hakim, L., Schmitt, T., Ducruix, S. \& CAndel, S. 2015 Dynamics of a transcritical coaxial flame under a high-frequency transverse acoustic forcing: influence of the modulation frequency on the flame response. Combust. Flame 162, 3482-3502.

Hardi, J. S., Martinez, H. C. G., Oschwald, M. \& Dally, B. B. 2014 LOx jet atomization under transverse acoustic oscillations. J. Propul. Power 30 (2), 337-349.

Hoeijmakers, M., Kornilov, V., Lopez Arteaga, I., De Goey, P. \& Nijmeijer, H. 2014 Intrinsic instability of flame-acoustic coupling. Combust. Flame 161 (11), 2860-2867.

HUO, H. \& YANG, V. 2011 Supercritical LOX/methane combustion of a shear coaxial injector. In 49th AIAA Aerosp. Sci. Meet. Exhib., Orlando, FL.

Myers, M. K. 1991 Transport of energy by disturbances in arbitrary steady flows. J. Fluid Mech. 226, 383-400.

Poinsot, T. J., Trouve, A. C., Veynante, D. P., Candel, S. M. \& Esposito, E. J. 1987 Vortex-driven acoustically coupled combustion instabilities. J. Fluid Mech. 177, 265.

RAYLEIGH, LORD 1878 The explanation of certain acoustic phenomena. Nature 18, 319.

Rogers, D. E. \& Marble, F. E. 1956 A mechanism for high-frequency oscillation in Ramjet combustors and afterburners. J. Jet Propul. 26 (6), 456-462.

Ruiz, A., Schmitt, T., Selle, L., Cuenot, B. \& Poinsot, T. 2011 Effects of the recess length of a coaxial injector on a transcritical $\mathrm{LO} 2 / \mathrm{H} 2$ jet flame. In $23 \mathrm{rd}$ ICDERS., Irvine, CA.

SCHMID, P. 2010 Dynamic mode decomposition of numerical and experimental data. J. Fluid Mech. 656, 5-28.

Schmitt, T., Méry, Y., Boileau, M. \& CAndel, S. 2011 Large-eddy simulation of oxygen/methane flames under transcritical conditions. Proc. Combust. Inst. 33 (1), 1383-1390.

Schuller, T., Durox, D. \& CAndel, S. 2003 A unified model for the prediction of laminar flame transfer functions: comparisons between conical and V-flame dynamics. Combust. Flame 134 (1-2), 21-34.

Searby, G. \& Rochwerger, D. 1991 A parametric instability in premixed flames. J. Fluid Mech. 231, 529-543.

Selle, L., Lartigue, G., Poinsot, T., Koch, R., Schildmacher, K.-U., Krebs, W., Prade, B., Kaufmann, P. \& Veynante, D. 2004 Compressible large eddy simulation of turbulent combustion in complex geometry on unstructured meshes. Combust. Flame 137 (4), 489-505.

Tucker, P., Menon, S., Merkle, C., Oefelein, J. \& Yang, V. 2008 Validation of high-fidelity CFD simulations for rocket injector design. In 44th AIAA/ASME/SAE/ASEE Jt. Propuls. Conf. Exhib. AIAA Paper 2008-5226. 
Urbano, A., Douasbin, Q., Selle, L., Staffelbach, G., Cuenot, B., Schmitt, T., Ducruix, S. \& CANDEL, S. 2017 Study of flame response to transverse acoustic modes from the LES of a 42-injector rocket engine. Proc. Combust. Inst. 36, 2633-2639.

Urbano, A., Selle, L., Staffelbach, G., Cuenot, B., Schmitt, T., Ducruix, S. \& Candel, S. 2016 Exploration of combustion instability triggering using large eddy simulation of a multiple injector liquid rocket engine. Combust. Flame 169, 129-140.

Wolf, P., Staffelbach, G., Gicquel, L. Y. M., Müller, J.-D. \& Poinsot, T. 2012 Acoustic and large eddy simulation studies of azimuthal modes in annular combustion chambers. Combust. Flame 159 (11), 3398-3413. 